\title{
Izboljšanje dostopa do trga za mala in srednje velika podjetja ter mikropodjetja v mestih Južnoafriške republike
}

Od demokratične spremembe leta 1994 se vladna politika v Južnoafriški republiki osredotoča na podpiranje malih in srednje velikih podjetij ter in mikropodjetij (MSMP). Zaradi visoke stopnje brezposelnosti in revšcine na mestnih območjih so posledice te interventne politike zelo pomembne za razvoj mest. Zaradi pestre zgodovine Južnoafriške republike želi vlada dati priložnost podjetjem $\mathrm{v}$ lasti temnopoltih Južnoafričanov, ki so bili med apartheidom prikrajšana skupina. $V$ članku avtor preučuje trenutne politične pobude, namenjene reševanju omejenega dostopa do trga, in obseg spodbujanja novih tržnih priložnosti za podjetja $\mathrm{v}$ lasti temnopoltih na mestnih območjih Južnoafriške republike. Poudarek je na dveh temah: povezovanju z oskrbovalnimi verigami zasebnega sektorja, zlasti prek zagotavljanja raznolikosti dobaviteljev, in povezovanju s trgi javnega sektorja prek javnih naročil. Iz političnih usmeritev je jasno, da ima vlada omejena pooblastila za izboljšanje položaja in konkurenčnosti MSMP $\mathrm{v}$ lasti temnopoltih, zato podpira pobude zasebnega sektorja. Poleg tega poskuša uresničevati, kar zagovarja, in uporabiti svoje možnosti izvajanja javnih naročil ter tako pomagati MSMP v lasti temnopoltih.

Ključne besede: dostop do trga, povezave, mala in srednje velika podjetja ter mikropodjetja, naročila zasebnega sektorja, javna naročila 


\section{Uvod}

Pri izpolnjevanju razvojnih ciljev tisočletja do leta 2015 se urbani deli Afrike spopadajo predvsem z ustvarjanjem novih »produktivnih zaposlitvenih priložnosti in delovnih mest za 7-10 milijonov mladih ljudi, ki vsako leto vstopijo na trg delovne sile in ki bodo večinoma živeli v mestih « (Thornton in Rogerson, 2013: 1). Presenetljivo je, da »so bile raziskave gospodarstva afriških mest vsaj v zadnjem desetletju močno zanemarjene « (Turok, 2010: 18). Ivan Turok (2012) navaja, da je treba nujno določiti politiko, ki bi okrepila gospodarstvo posameznih afriških mest in omogočila, da bi bile vanj enakovredno vključene vse skupine prebivalstva. Zaradi omejenih možnosti ustvarjanja delovnih mest $\mathrm{v}$ velikih zasebnih, vladnih in psevdodržavnih podjetjih se je začela politika mnogih držav vse bolj osredotočati na ustvarjanje priložnosti zaposlovanja v malih in srednje velikih podjetjih ter mikropodjetjih (MSMP), ki predstavljajo večino podjetij v podsaharski Afriki (Rogerson, 1997, in Kessides, 2007). Obstaja vprašanje, ali se lahko masa MSMP izboljša in preoblikuje $\mathrm{v}$ produktivnejša rastoča podjetja, ki zagotavljajo boljši zaslužek, primerne delovne priložnosti in davčne prihodke, $s$ katerimi bi lahko financirali tudi izboljšane javne storitve in infrastrukturo (Turok, 2012). Za afriške urbane predele je značilna »neformalnost «, torej neformalni gospodarski prostori in neformalno delo, za katero delavci ne dobijo ustreznega plačila; to je običajno posledica nasičenih trgov in pomanjkanja kapitala, neustrezne usposobljenosti in tehnologije (Grant, 2010; Meagher, 2010, in Turok, 2010). Nekateri analitiki menijo, da ima rast afriške neformalne ekonomije običajno ekstenziven značaj, pri čemer se množijo iste oblike neformalnih podjetij, namesto da bi se mala podjetja močneje uveljavila in postala bolj dinamična (na primer Rogerson, 1997; Bryceson in Potts, 2006, in Turok, 2012). Na afriških mestnih območjih je nujno treba vzpostaviti okolje, ki bo spodbujalo dinamično gospodarstvo in tako omogočalo razvoj malih podjetij. V Afriki ta problem preprečuje razvoj čvrstega lokalnega gospodarstva in njegovo izgradnjo, kar se najbolj pozna v mestih (Kessides, 2007; Rogerson, 2010; Rogerson in Rogerson, 2010, ter Thornton in Rogerson, 2013). Kot poudarjata Ivan Turok in Susan Parnell (2009), reševanje mnogih ključnih problemov hitrega razvoja afriških mest presega zmožnosti lokalnih uprav, da bi se ustrezno odzvale.

Več avtorjev poudarja možnost nujne skupne državne pomoči, $s$ katero bi lažje izboljšali položaj malih podjetij in jim tako omogočili dinamično rast (Rogerson, 1997; Bryceson in Potts, 2006, in Turok, 2010). Prav tako dvomijo, da je »nacionalna država « zmožna izboljšati položaj malih podjetij. Ena afriških držav, v kateri se že dolgo sprejemajo pobude za podporo in razvoj MSMP, je Južnoafriška republika. Od demokratične spremembe leta 1994 se vladna politika v Južnoafriški republiki osredotoča na spodbujanje podjetništva in razvoj MSMP (Ro- gerson, 2004a in 2004b; Urban, 2006, in Timm, 2011). Po dveh desetletjih brezposelnost in slabe možnosti zaslužka še naprej spodjedajo južnoafriška mesta (Boraine idr. 2006; Turok in Parnell, 2009; Freund, 2010; Grant, 2010; Schenck in Blaauw, 2011, in Ligthelm, 2012). Celo dvajset let po koncu apartheida je zaradi trdovratne brezposelnosti in velike revščine po vsej državi in zlasti v največjih mestih razvoj MSMP še vedno eden prednostnih ciljev vladne politike. $V$ novejšem nacionalnem razvojnem načrtu do leta 2030 je ponovno poudarjen pomen izboljšanja položaja MSMP (urad predsednika Južnoafriške republike, 2011). Podobno tudi ključna gospodarska strategija z naslovom Nova pot rasti (ang. New Growth Path) ter dokumenti ministrstva za trgovino in industrijo (ang. Department of Trade and Industry, v nadaljevanju: DTI), ki je odgovorno za gospodarstvo in s tem tudi za razvoj podjetij, še naprej poudarjajo podporo MSMP (ministrstvo za gospodarkki razvoj, 2010; DTI, 2011). Zaradi zgodovine se vladna politika osredotoča predvsem na izboljšanje možnosti tistih podjetij, ki so jih ustanovili in jih imajo $\mathrm{v}$ lasti temnopolti Južnoafričani, ki so bili med apartheidom prikrajšana skupina. Težave in omejitve te velike skupnosti MSMP (večino te tvorijo mestna podjetja, ki služijo na črno) je obravnavalo in analiziralo več avtorjev (Rogerson, 2004b, 2004c, 2006 in 2008; Timm, 2011, in Ligthelm, 2012). Predvsem pa so glavne težave malih podjetij, ki so usmerjena $\mathrm{v}$ rast, zlasti v mestih povezane z nizom zapletenih vprašanj, in sicer s slabim dostopom do trga in financ in pomanjkljivostmi podpornega okolja.

Namen članka je preučiti vrsto sodobnih političnih pobud vlade in zasebnega sektorja za reševanje vprašanj dostopa do trga in oblikovanja novih tržnih priložnosti za podjetja v Južnoafriški republiki, ki so v lasti temnopoltih. Čeprav je razvoj MSMP na podeželju v Južnoafriški republiki pereče vprašanje, se vladni posegi za razvoj MSMP osredotočajo predvsem na spodbujanje gospodarskega razvoja v večjih mestih in središčih. Kot že rečeno, ta položaj omogoča nujno potrebno povezovanje vladne politike $\mathrm{z}$ lokalnimi potrebami po spodbujanju razvoja MSMP v okviru lokalnih razvojih programov (glej Nel in Rogerson, 2005; Rogerson, 2011, ter Rogerson in Rogerson, 2012). Avtorjeva analiza prispeva k boljšemu razumevanju osnovne politične dinamike, ki na državni ravni vpliva na nastajajočo pokrajino MSMP v južnoafriških mestih. Poudarek je na malih podjetjih, usmerjenih $\mathrm{v}$ rast, in ne na vprašanjih, povezanih z neformalnimi podjetji, ki služijo na črno. Slednje bi bilo treba obravnavati in analizirati ločeno.

$\mathrm{V}$ članku so uporabljene različne oziroma mešane metode. Najprej so bili opravljeni intervjuji z vplivnimi predstavniki vlade, zasebnega sektorja in MSMP. Med glavnimi déležniki in oblikovalci politike, ki so v intervjujih sodelovali med letoma 2009 in 2010, so bili predstavniki DTI, ministrstva za finance, agencije za razvoj malih podjetij, nacionalne poslov- 
ne pobude (ang. National Business Initiative, v nadaljevanju: NBI) kot organa zasebnega sektorja in državnega svetovalnega odbora za mala podjetja. Nato so bili podatki, pridobljeni v intervjujih, primerjani $z$ dokumentarnim gradivom, tudi $z$ internimi organizacijskimi poročili o napredku izvajanja politike razvoja MSMP v Južnoafriški republiki. Ugotovitve te analize so bile nato predstavljene na delavnici, ki so se je udeležili vsi omenjeni ključni déležniki dejavnosti MSMP.

Avtor se osredotoča na dve temi: povezovanje z oskrbovalnimi verigami zasebnega sektorja, zlasti prek raznolikosti dobaviteljev, in povezovanje s trgi javnega sektorja prek javnih naročil. Pomen teh dveh tem je poudarjen tudi v nacionalnem razvojnem načrtu, ki določa, da »bodo javna in zasebna naročila glavni spodbujevalnik povpraševanja po storitvah malih in rastočih podjetij « (urad predsednika Južnoafriške republike, 2011: 119). Članek je razdeljen na tri poglavja, v katerih avtor obravnava spreminjajoče se smeri vladne politike v Južnoafriški republiki glede problematike razvoja MSMP. Temu sledi kritična analiza nastajajočih političnih pobud za povezovanje naročil zasebnega sektorja in ustvarjanje priložnosti za razvoj MSMP pri naročilih zasebnega sektorja. Članek prispeva $\mathrm{k}$ bolǰ̌emu razumevanju spreminjajoče se usode velikega dela MSMP v Južnoafriški republiki, ki pomembno vpliva na zaposlovanje v mestih. Poleg tega skromno prispeva $k$ omejeni zbirki raziskav s področja razvoja malih podjetij v afriških mestih. Študija politike razvoja MSMP v Južnoafriški republiki, ki je med najbolj izdelanimi na afriški celini, vsebuje novo znanje in ugotovitve, ki jih lahko uporabijo tudi druge afriške države.

\section{MSMP v Južnoafriški republiki: izzivi in politični odzivi}

Poleg slabega dostopa do financ ter neurejenega zakonodajnega in podpornega okolja je glavna težava MSMP v mestih Južnoafriške republike, zlasti nastajajočih podjetij v lasti temnopoltih, slab dostop do trga (Timm, 2011). To je glavni vzrok za propadanje podjetij in izgubo strank v MSMP. V Južnoafriški republiki ločimo tri glavne vidike tržnega dostopa različnih MSMP.

Prvi vidik je povezan s sektorsko zasičenostjo, ki je posledica tega, da se večina malih mestnih podjetij zgošča v dejavnostih in gospodarskih segmentih, ki imajo slabe možnosti za rast. V dejavnostih, kot je trgovina, so zaradi zasičenosti mogoči le nizki prihodki in zato večina podjetij posluje na robu preživetja. Pri izboljšsanju dostopa do trga bi bilo treba s političnimi ukrepi doseči večjo razvejanost dejavnosti, pri čemer se mala podjetja ne bi več zgoščala v dejavnostih z nizkim potencialom rasti, ampak bi se preusmerila v dejavnosti z višjim potencialom. Drugi vidik se nanaša na probleme dostopa do trga zaradi lokacije podjetij. Številna mala podjetja, ki prodajajo blago in ponujajo storitve, se spopadajo s tržno omejenostjo zaradi slabe geografske dostopnosti. Zaradi tržne omejenosti, ki je posledica lokacije podjetij, ki omejuje njihov dostop, so ta podjetja $\mathrm{v}$ neugodnem položaju, ki se kaže na državni ravni pri podjetjih na oddaljenih oziroma podeželskih območjih in tudi v mestih, v katerih so mnogi prikrajšani podjetniki prisiljeni poslovati na obrobju. Tretji in najpomembnejši vidik, povezan $\mathrm{z}$ dostopom do trga, se nanaša na razvoj konkurenčnosti malih podjetij v lasti temnopoltih, ki dobavljajo blago in storitve (običajno so taka podjetja $\mathrm{v}$ lasti belcev) ter bi lahko postala člen $\mathrm{v}$ oskrbovalni verigi javnega in zasebnega sektorja. $V$ kontekstu globalizacije bi tako lahko določene kategorije (skoraj izključno mestnih) MSMP postale konkurenčne ne samo v domačih, ampak tudi v svetovnih oskrbovalnih verigah.

Pregled skoraj dvajsetletnega programa vladne pomoči in ukrepov za razvoj MSMP v Južnoafriški republiki kaže, da je bilo reševanje slabega dostopa do trga rdeča nit politike državne podpore vse od leta 1994. Leta 1995 so bile za podporo lokalnih MSMP na podlagi mednarodnih primerov dobrih praks vpeljane popolnoma nove politične pobude in ustanovljene nove institucije (Rogerson, 2004b). Pobude so zajemale tudi ustanovitev ločenih institucij za področje financ, nefinančnih zadev in spodbujanje sklepanja podizvajalskih pogodb. Ključni dosežki prvega desetletja podpiranja MSMP so povezani z izgradnjo nove arhitekture za namene MSMP, ki je bila med apartheidom večinoma zanemarjena. Žal je le nekaj MSMP, ki so prejela pomoč, širilo svoje poslovanje, zaradi omejenih financ, dodeljenih temu programu, pa je le malo sredstev doseglo podjetja v lasti temnopoltih, ki so se borila za obstanek. Vzroki za neuspeh so bili omejena sredstva, slabo usklajevanje in izvajanje politike ter dejstvo, da je lahko obstoječo politiko izkoristila predvsem skupina srednje velikih podjetij, ki so bila večinoma v lasti belcev, in ne nastajajoča MSMP v lasti temnopoltih, ki naj bi bila ciljna skupina programa. Ta so ostala na gospodarskem obrobju (Rogerson, 2004b).

Zaradi neuspeha sta bila politični okvir in delovanje ustanov ponovno ocenjena. Po letu 2006 je bila vpeljana nova strategija integriranega razvoja malih podjetij (ang. Integrated Small Business Development Strategy, v nadaljevanju: DTI, 2006). Temeljila je na treh stebrih podpore MSMP: povečanju dostopa MSMP do posojil in financ, izboljšnju dostopa do trga in oblikovanju reforme zakonodaje (DTI, 2006). Poleg tega je bil oblikovan tudi nov institucionalni okvir podpore, $\mathrm{v}$ sklopu katerega je bila ustanovljena državna agencija za razvoj malih podjetij, ki naj bi skrbela za bolǰ̌e usklajevanje in vključevanje političnih pobud. Uspešnost novega sistema podpore v obdobju 2006-2011 je preučila južnoafriška organizacija Osiba Research (2011). Glavne ugotovitve raziskave so ponovno potrdile, da vladni programi razvoja večine MSMP v lasti te- 
mnopoltih ne podpirajo dovolj in jih ne vključujejo dovolj v formalno gospodarstvo. Opozoriti je treba, da se ocena nanaša na obdobje politike, v katerem je vlada dejavneje podpirala nastajajoča MSMP $\mathrm{v}$ lasti temnopoltih kot $\mathrm{v}$ prvem desetletju posegov s področja politike MSMP po koncu apartheida.

Ugotovimo lahko, da je neuspeh južnoafriških MSMP treba pripisati predvsem temu, da vlada ni sposobna izvajati programov podpore, in ne neustreznim strategijam (Osiba Research, 2011). Pri obravnavi te teme lahko preučujemo tudi vprašanje dostopa MSMP do trga. Prizadevanja za izboljšanje dostopa do trga se zdaj osredotočajo predvsem na dve strateški pobudi, in sicer na večje sodelovanje z zasebnim sektorjem, ki naj bi v svoja naročila vključil tudi MSMP, ter boljšo rabo javnih trgov in javnih naročil za izboljšanje dostopa do trga.

\section{Pobude, povezane $z$ naročili zasebnega sektorja}

V obsežnem delu mednarodne literature se zagovarja stališče, da z gospodarskim povezovanjem najhitreje in najučinkoviteje izboljšamo položaj MSMP, saj med drugim povečamo njihov dostop do trga in do financ (konferenca Združenih narodov o trgovini in razvoju, 2006). Dejavnosti mednarodnih agencij, donatorjev in vlad so spodbudile veliko različnih pobud za pospeševanje poslovnega povezovanja. Spodbujanje poslovnega povezovanja z MSMP je dobro tako z vidika konkurenčnosti kot družbene odgovornosti gospodarskih družb (Jenkins, 2007, ter Jenkins in Ishikawa, 2009). Večina mednarodnih primerov kaže, da velike gospodarske družbe zaradi poslovnih razlogov oblikujejo in podpirajo programe povezovanja z MSMP, ki ponujajo blago in storitve. Potrjujejo, da je »raznolikost dobaviteljev « vse pomembnejši pojav v poslovni strategiji (Rogerson, 2012). V skladu s tem se večina raziskav MSMP osredotoča na pomen spodbujanja »raznolikosti dobaviteljev« in posege, ki so izdelani posebej za ustvarjanje raznolikosti znotraj programov razvoja MSMP. V mnogih državah je spodbujanje raznolikosti dobaviteljev glavna tema razprav o razvoju MSMP in osrednje vprašanje politike tega območja (Ram in Smallbone, 2003a in 2003b, in Sonfield, 2010). Vprašanja, povezana z raznolikostjo dobaviteljev, so postala zlasti pomembna v ZDA, Združenem kraljestvu in v zadnjem času tudi v Avstraliji. Pri obravnavi raznolikosti dobaviteljev se v ZDA osredotočajo na spodbujanje » podjetij, ki so v lasti manjšin «, v Veliki Britaniji na spodbujanje » podjetij, ki so v lasti etničnih manjšin «, in v Avstraliji na »priložnosti za domorodce « (Rogerson, 2012). Henry Adobor in Ronald McMullen (2007: 219) potrjujeta, da postaja raznolikost dobaviteljev vse pomembnejša, ker so velika podjetja »prepoznala ekonomske koristi širjenja svoje baze dobaviteljev na podjetja, ki so v lasti manjšin «.
Kot poudarja David Toomey (1998), v Južnoafriški republiki pobude za vključitev MSMP (tudi temnopoltih dobaviteljev) v oskrbovalne verige velikih podjetij v zasebnem sektorju segajo vse do obdobja apartheida. V 80. letih in na začetku 90. let 20. stoletja so rudniška in nekatera druga vodilna podjetja sprožila vplivne pobude za izboljšanje zmogljivosti podjetij v lasti temnopoltih in njihovo vključitev $\mathrm{v}$ oskrbovalne verige gospodarskih družb (NBI, 2006a). Več zgodnjih programov je bilo negospodarsko motiviranih, saj je bil njihov glavni cilj pridobiti lokalno dovoljenje za poslovanje $\mathrm{v}$ določenih skupnostih; »dolgoročno pa so imeli poslovne motive « (NBI, 2006b: 6). Pred letom 1994 so bile pobude zasebnega sektorja za večje možnosti oddaje del s strani rudniških podjetij prej izjema kot pravilo, poleg tega so imele le omejen lokalni vpliv. David Toomey (1998: 136) poudarja, da »je bil pred letom 1994 zasebni sektor komaj prisoten $\mathrm{v}$ programih podpore novih temnopoltih podjetnikov, čeprav naj bi imela zasebna industrija z njimi največ izkušenj in bi jim tako lahko najbolje pomagala «. Poleg tega je bilo jasno, da se je »večina primerov povezovanja med podjetji v Južnoafriški republiki nanašala na ukrepe, ki jih lahko najbolje opišemo kot družbeno odgovornost podjetij in dobrodelna dejanja in ki niso spadali v glavno dejavnost podjetja « (Toomey, 1998: 148). Po demokratični spremembi so potrebe po ponovni oživitvi gospodarstva, okrepitvi proizvodne strukture in zagotavljanju večje gospodarske vključenosti vseh družbenih skupin pokazale, da družbena odgovornost podjetij preprosto ni mogla zadovoljiti novih pričakovanj, zlasti na mestnih območjih.

Takoj po nastopu novega demokratičnega obdobja so se okrepila prizadevanja za zagotavljanje novih tržnih priložnosti za MSMP s spodbujanjem tržnih povezav med MSMP in velikimi gospodarskimi družbami. Učinek teh pobud v prvem desetletju demokracije je bil vseeno omejen (Rogerson, 2004a). Od leta 2005 vlada agresivneje pristopa $\mathrm{k}$ izboljšanju priložnosti, povezanih z naročili znotraj zasebnega sektorja. Pomembno je bilo sprejetje zakona o krepitvi gospodarske moči temnopoltega prebivalstva (ang. Broad-Based Black Economic Empowerment Bill, v nadaljevanju: B-BBEE) leta 2004; gre za glavni pravni instrument, ki pokriva najrazličnejša vprašanja, tudi uvedbo preferencialnega javnega naročanja. Za mnoge je B-BBEE »ena ključnih poslovnih obvez sedanjosti in prihodnosti« (Juggernauth idr., 2011). B-BBEE naj bi » pozornost preusmeril na prispevek južnoafriških podjetij $\mathrm{k}$ ponovnemu reševanju problema gospodarskih in socialnih neravnovesij v državi« (Skae, 2006: 4). Osnovni namen tega zakona je bilo »na podlagi sistema usklajevanja zagotoviti, da vsak subjekt, ki želi izpolniti zahteve za pridobitev dovoljenja ali koncesije, dobavljati blago ali storitve kateremu koli državnemu organu ali javnemu subjektu, kupiti državna podjetja ali sodelovati v javno-zasebnih partnerstvih, pokaže zavezanost krepitvi gospodarske moči temnopoltega prebivalstva « (Skae, 2006: 4). 
Politično ozračje za povečanje števila naročil javnega in zasebnega sektorja se je še izboljšalo $s$ sprejetjem kodeksa dobrih praks B-BBEE leta 2007 in z njim povezanega sistema uravnoteženih kazalnikov (ang. balanced score card; Herrington in Overmeyer, 2006). Glavni namen kodeksa sta bila » pomoč in svetovanje javnemu in zasebnemu sektorju pri izvajanju ciljev $\mathrm{B}-\mathrm{BBEE}$ « na pomemben in trajnosten način (Botha in Van Vuuren, 2006: 8). Če poenostavimo: boljši rezultat ko podjetje doseže pri meritvi uravnoteženih kazalnikov B-BBEE, lažje lahko sklepa posredne ali neposredne posle z lokalno, regionalno ali državno upravo ter državnimi podjetji v Južnoafriški republiki. Uvedba preferencialnega naročanja je bila ena najpomembnejših prvin splošnega sistema uravnoteženih kazalnikov, ki ga je ministrstvo za trgovino in industrijo uvedlo za merjenje napredka podjetij pri doseganju ciljev B-BBEE. Kodeks dobrih praks poudarja »preferencialno naročanje, ki uveljavljena podjetja spodbuja, da naročajo storitve od podjetij v lasti temnopoltih « (Herrington in Overmeyer, 2006: 8). Ta pristop v bistvu spodbuja sodelovanje na podlagi tržnega dostopa in podjetja temnopoltih vključuje $\mathrm{v}$ formalno gospodarstvo.

V skladu s sistemom uravnoteženih kazalnikov naj bi gospodarske družbe najmanj $20 \%$ naročil dodelile podjetjem v lasti temnopoltih. Mnoge raziskave pa so pokazale, da se je precej velikih podjetij upiralo in premalo zavzelo, da bi podprlo temnopolte dobavitelje, zaradi česar so slabo prispevala $\mathrm{k}$ boljši konkurenčnosti MSMP (Herrington in Overmeyer, 2006, in Rogerson, 2012). Za odpor velikih podjetij do povezovanja $\mathrm{z}$ nastajajočimi podjetji $\mathrm{v}$ lasti temnopoltih je več razlogov: nezmožnost MSMP, da zadovoljijo potrebe in zahteve velikih podjetij; neuresničeno »partnerstvo enakih « in odvisnost malih podjetij od posameznih povezav z večjimi podjetji ter omejen obseg koristnih poslovnih praks velikih podjetij, ki bi podpirale povezave z MSMP (NBI, 2006a). Največje težave so povezane $\mathrm{z}$ omejenim dostopom do informacij o poslovnih priložnostih, $s$ kratkoročnostjo pogodb, plačilnimi krogi, ki MSMP povzročajo težave $z$ denarnimi tokovi, in $\mathrm{z}$ le omejeno rabo javnih naročil, ki se oddajo za posebne namene (ang. set-asides), ter $s$ preklici pogodb in garancij za dobro izvedbo pogodbenih obveznosti. Druge težave so povezane s premalo zavzetim vodstvom $\mathrm{v}$ velikih družbah (zlasti pri osebju, zadolženem za sklepanje javnih naročil z MSMP) in potrebo po tem, da velika podjetja spremenijo svoje dojemanje poslovnih povezav kot oblik družbenih naložb podjetij (NBI, 2006a).

Kljub zakonodaji, ki velika podjetja v Južnoafriški republiki spodbuja k vključitvi MSMP v oskrbovalne verige do leta 2050, razlogi za poslovno povezovanje $\mathrm{v}$ zasebnem sektorju temeljijo na vse več lokalnih in mednarodnih primerih, ki podpirajo povezovanje in raznolikost dobaviteljev. $\mathrm{V}$ preteklosti so velike gospodarske družbe $\mathrm{v}$ Južnoafriški republiki raje sodelovale $\mathrm{z}$ velikimi (večinoma belskimi) dobavitelji (Toomey, 1998, ter Herrington in Overmeyer, 2006). Tako kot v ZDA in Združenem kraljestvu so velika podjetja vse bolj priznavala poslovne razloge za spodbujanje pobud zasebnega sektorja, katerih cilj je bil razširiti vrednostne verige in vanje vključiti mala podjetja v lasti temnopoltih. Nacionalna poslovna pobuda je močno vplivala na popularizacijo »poslovnih razlogov oblikovanja trgovskih vezi med velikimi in malimi podjetji v Južnoafriški republiki« (NBI, 2006a: 4). Poudarjala je, da »lahko vezi med podjetji občutno izboljšajo vrednostno verigo javnega naročanja, proizvodnje, trženja in prodaje v določeni panogi« (NBI, 2006a: 27). Poudarek je na priložnostih velikih podjetij, da okrepijo svoj preboj na trg, in na prednostih, ki jih prinaša » prožnost malih podjetij «, in sicer bolj ekonomično obdelavo majhnih naročil (NBI, 2006b: 14).

$\mathrm{V}$ splošnem so se poslovne povezave $\mathrm{v}$ Južnoafriški republiki oblikovale tako, da so velika podjetja od malih kupovala različno blago in storitve, $s$ čimer so širila svoje prodajne in podizvajalske mreže (Skae, 2006). Druge oblike sodelovanja $\mathrm{v}$ vrednostnih verigah podjetij, kot sta oblikovanje in razvoj izdelkov, so bile redke. Velik neizkoriščen potencial malih podjetij so tudi prednosti, ki jih prinašata njihova glavna dejavnost in lokacija, saj bi lahko postala pomemben distribucijski kanal za velika podjetja (NBI, 2006a). Glavni dejavniki, ki naj bi spodbujali poslovno povezovanje med malimi in velikimi podjetji v Južnoafriški republiki, večinoma sledijo mednarodnim zgledom in vsebujejo: povečanje zmogljivosti malih podjetij, nadzorovanje kršitev B-BBEE, izogibanje odvisnostnim odnosom, izboljšanje dostopa malih podjetij do informacij, uporabo krajših plačilnih krogov, možnost odpovedi pogodb, izboljšanje dostopa do financ $\mathrm{z}$ izdajanjem garancij za dobro izvedbo pogodbenih obveznosti, možnost usklajevanja cen kot del poenostavljenega razpisnega postopka, zagotavljanje zavzetega vodstva, ki podpira poslovno povezovanje, in spodbujanje širšega podpornega okolja za razvoj MSMP prek vladnih podpornih programov (Herrington in Overmeyer, 2006, in NBI, 2006b). Izkazalo pa se je, da vladne pobude za pomoč MSMP niso bile učinkovite za tista podjetja, ki bi se lahko povezala $\mathrm{z}$ velikimi podjetji, in da je doslej zasebni sektor $\mathrm{v}$ Južnoafriški republiki redkokdaj sodeloval pri oblikovanju podpornega sistema za oddajo naročil MSMP (NBI, 2006b).

Zaradi očitnega premika vladne politike od podpore MSMP $\mathrm{h}$ krepitvi gospodarske moči temnopoltega prebivalstva (ang. Black Economic Empowerment, v nadaljevanju: BEE) so se številna velika zasebna podjetja začela osredotočati na BEE. Zaradi veljavne zakonodaje velika podjetja pogosto dajejo prednost ciljem B-BBEE in ne razvoju podjetništva; zelo »malo se jih osredotoča na lokalno vsebino in razvoj lokalnih dobaviteljev « (Altman, 2010: 41). Velika podjetja lahko izpolnjujejo pogoje akreditacije $\mathrm{BEE}$, tudi če se ne posvečajo razvoju podje- 
tništva. Mnoge južnoafriške gospodarske družbe so oblikovale bolj ali manj uspešne programe in strukture, $s$ katerimi naj bi dosegle vladne cilje preferencialnega javnega naročanja in razvoja podjetništva. $\mathrm{V}$ večini primerov gre za programe, ki so ločeni od poslovne strategije in glavnih dejavnosti podjetja ter se pogosto obravnavajo kot nujno zlo poslovanja in ne kot vložek v konkurenčnost in trajnostni razvoj podjetja.

Razprave o poslovnih vezeh v Južnoafriški republiki so se postopoma preusmerile na vprašanja » raznolikosti dobaviteljev «, čeprav se ne osredotočajo na » podjetja v lasti manjšin «, ampak na podjetja $\mathrm{v}$ lasti večinskega, to je temnopoltega, prebivalstva v državi. Poudarek je na vlogi velikih organizacij zasebnega sektorja, ki pomagajo izboljšati zmogljivost in konkurenčnost zgodovinsko neprivilegiranih MSMP in jih povezati s trgom. Pomembna prelomnica je bila ustanovitev južnoafrǐškega sveta za raznolikost dobaviteljev (ang. South African Supplier Diversity Council, v nadaljevanju: SASDC) leta 2010; to je vzporedna organizacija ameriškemu nacionalnemu svetu za raznolikost manjšinskih dobaviteljev in del svetovne mreže svetov za raznolikost dobaviteljev (SASDC, 2011). Cilj SASDC je postati glavni spodbujevalec trajnostne dodane vrednosti, ki jo prinaša raznolikost dobaviteljev, na podlagi usmerjenega javnega naročanja in razvoja temnopoltih dobaviteljev. SASDC poudarja šest poslovnih razlogov za vključevanje raznolikih dobaviteljev v strategijo oskrbovalnih verig podjetij: izboljšana konkurenčnost oskrbovalne verige, inovativnost proizvodov prek sodelovanja z novimi dobavitelji, povečana prepoznavnost blagovne znamke podjetja med lokalnimi skupnostmi, déležniki in vlado, izboljšana tržna inteligenca zaradi tesnejših odnosov z dobavitelji, večji tržni delež in zvestoba ter boljši dostop do poslovnih priložnosti javnega (in zasebnega) sektorja z izpolnjevanjem meril BEE (SASDC, 2011). V svojem bistvu SASDC poganja proces podjetniške preobrazbe v Južnoafriški republiki, pri čemer je njegov strateški cilj omogočiti svojim članom, da se zavzemajo za raznolikost dobaviteljev na podlagi treh glavnih dejavnosti (Joseph, 2010).

Prva dejavnost vključuje oblikovanje in vzdrževanje podatkovne zbirke certificiranih temnopoltih dobaviteljev, do katere lahko dostopajo člani sveta. Postopek certifikacije, ki ga uporablja SASDC, je strog tako z vidika preverjanja lastniškega statusa in preprečevanja kršitev B-BBEE kot zagotavljanja kakovostnih dobaviteljev, ki so zmožni dobavljati blago in storitve po standardih članov sveta (Ismail in Haselau, 2010). Druga dejavnost vključuje širjenje dobrih praks in znanja $s$ področja raznolikosti dobaviteljev, tretja dejavnost pa se osredotoča na podpiranje članov, da povečajo naročila in razvojne možnosti podjetij v lasti temnopoltih. Med glavnimi posegi so usklajevanje cen, spodbujanje pedagoških raziskav za širjenje podjetij v lasti temnopoltih, organizacija poslovnih sejmov in dogodkov - v okviru katerih lahko podjetja spoznajo nove stranke ter ki naj bi olajšali oblikovanje poslovnih vezi med člani SASDC in certificiranimi temnopoltimi dobavitelji - ter pomoč članom pri vzpostavljanju, izvajanju in širjenju programov ciljnih javnih naročil (SASDC, 2011).

Leta 2010 je zasebni sektor brez vladne podpore začel uvajati pobude za razvoj raznolikosti dobaviteljev. $S$ tem se je v Južnoafriški republiki odprlo novo poglavje, v katerem so naročila zasebnega sektorja orodje, ki MSMP v lasti temnopoltih omogoča, da postanejo del oskrbovalnih verig večjih podjetij; vlada je dejavnosti SASDC odobrila leta 2011 in 2012. Vlada zdaj vlogo zasebnega sektorja, pobudnika povezovanja s podjetji v lasti temnopoltih, podpira z razširjenim programom naročil zasebnega sektorja, ki bi lahko dopolnjeval vladne podporne programe.

\section{Naročila javnega sektorja}

Javno naročanje, ki je ena glavnih vladnih funkcij, doslej ni bilo dovolj raziskano (Thai, 2001; Mahmood, 2010). Javno naročanje je v mnogih državah gibalna sila razvoja MSMP, zlasti javna naročila, ki se oddajajo za posebne namene in omogočajo tržni dostop nekaterim izbranim skupinam MSMP. »Južnoafriška republika bi lahko zagotovila pomoč malim podjetjem, če bi določene vrste javnih naročil oddala malim in srednje velikim podjetjem, kot to že počnejo številne države, na primer Južna Koreja, ZDA in Japonska « (Timm, 2011: 43). V Kanadi se javna naročila za posebne namene uporabljajo pri vladnih pogodbah, ki določajo obvezno vključevanje »domorodnih « dobaviteljev (Orser, 2009: 23). »Pri javnih naročilih za posebne namene se določena naročila rezervirajo za določeno skupino prikrajšanih lastnikov malih in srednje velikih podjetij, ki lahko sodelujejo pri razpisu, « in ne za pomoč malim podjetjem iz prikrajšanih skupin v splošnem (Orser, 2009: iii). Javna naročila, ki se oddajajo za posebne namene, so prožna orodja, ki se v ZDA množično uporabljajo za pomoč malim podjetjem $\mathrm{v}$ splošnem in za podporo natančno določenim ciljnim skupinam malih podjetij, kot so podjetja v lasti žensk ali pripadnikov manjšin (Bates, 2001, in House-Soremekun, 2007). Čeprav so učinki teh programov sporni, jih veliko strokovnjakov hvali ter poudarja, da so bili » potrebni za ustvarjanje enakih pogojev in priložnosti za ustanavljanje in rast podjetij v lasti pripadnikov manjšin « (Sonfield, 2010: 12). Ena od posledic preferencialnega javnega naročanja je bilo to, da so se za taka podjetja odprli novi trgi, zaradi česar so lahko bolj razvejala svoje dejavnosti ter tako niso več ponujala samo trgovskih in osebnih storitev.

Phoebe Bolton (2006) poudarja, da je bil pred demokratično spremembo leta 1994 vladni sistem javnega naročanja $\mathrm{v}$ Južnoafriški republiki naklonjen predvsem velikim in že uveljavljenim podjetjem. V takem okolju so mala podjetja zelo 
težko prišla do javnih naročil. Leta 1994 pa je javno naročanje postalo ustavna pravica, prepoznana kot sredstvo odpravljanja preteklih diskriminacijskih praks (Bolton, 2008). Postalo je politično orodje, ki naj bi »popravilo zgodovino Južnoafriške republike « (Bolton, 2006: 202). Izjemno pomembno je, da vladni organi pri javnem naročanju blaga in storitev in oddaji naročil upoštevajo različne dejavnike. Kot poudarja P. Bolton (2006: 202), ima pojem »opolnomočenja « »pomembno vlogo pri odločanju, ali se naročilo odda določenemu izvajalcu «. Izvaja se strategija, znana kot » afirmativno « ali »ciljno « javno naročanje, ki naj bi »zagotavljala zaposlitvene in poslovne priložnosti marginaliziranim posameznikom in skupnostim oziroma ,ciljnim skupinam' « (Bolton, 2008: 2). Poleg tega, da se vladna politika osredotoča na krepitev gospodarske moči temnopoltega prebivalstva, je vse več zanimanja za uporabo javnega naročanja kot strateškega orodja za doseganje ciljev strategij razvoja MSMP. Leta 2007 je južnoafriška vlada sprejela » pobudo desetih izdelkov «, v skladu s katero bi vlada od MSMP v lasti temnopoltih kupovala samo določene izdelke. $\mathrm{V}$ skladu z vladnim preferencialnim naročanjem izdelkov in storitev malih podjetij je bilo izbrano deset kategorij izdelkov in storitev, ki naj bi jih dobavljala MSMP, in sicer: oglaševanje, mediji in komuniciranje; zunanje in notranje čišcenje; oblačila in tekstil; računalniška oprema in potrošni material; zunanje in notranje pohištvo in oprema; organizacija in vodenje prireditev; vzdrževanje in popravila, gradbeništvo, kleparska in ličarska popravila; organizacija potovanj in prevozov na letališče; gostinstvo; pisalne potrebščine in tiskanje (Kaiser Associates, 2010).

Pobuda pa se ne izvaja tekoče; vlada spodbuja zasebni sektor in od njega vse bolj zahteva, naj upošteva kodeks B-BBEE in širi svoje povezave s podjetji v lasti temnopoltih, vendar sama tega ne izvaja pri svojih naročilih. Čeprav je sprejela sklep o desetih ciljnih storitvah, ki naj bi se od MSMP dobavljale pri vseh javnih naročilih, se ta do leta 2012 še ni začel izvajati. Kot navaja Stephen Timm (2011: 46), je med razlogi za to tudi dejstvo, da se finančno ministrstvo »podobno kot številne vlade po svetu najverjetneje boji, da bi javna naročila za posebne namene povečala stroške javnih naročil «. V intervjujih $s$ predstavniki finančnega ministrstva je postalo jasno, da so glavni zadržki pri tovrstnih naročilih ter načrtu naročanja deset ciljnih izdelkov in storitev povezani $\mathrm{z} \gg$ neustavno « naravo. Kot pojasnjuje Nomonde Mesatywa (2011), ima finančno ministrstvo izjemen vpliv na sprejemanje medresorskih odločitev. Običajno »državni organi sledijo uredbam finančnega ministrstva «, zaradi česar se zakon B-BBEE $\mathrm{v}$ javnem naročanju večinoma ne izvaja (Mesatywa, 2011: 9).

Trenutna podpora je torej povezana $\mathrm{z}$ izvajanjem zakona o preferencialnem javnem naročanju, pri katerem imajo temnopolti dobavitelji prednost pri dodeljevanju naročil. Druge pobude so povezane $\mathrm{z}$ ustanovitvijo nacionalnega spletnega portala javnih naročil, katerega namen je izboljšati dostop do trga z oblikovanjem platforme, ki bo združevala vse podatke o javnih naročilih in razpisih ministrstev. Portal bo izboljšal dostop do informacij za dobavitelje in kupce ter tako okrepil sodelovanje malih podjetij pri javnem naročanju in zbiranju ponudb. Poleg tega bodo postopki javnega naročanja učinkovitejši, saj se bodo MSMP znebile administrativnega bremena. Portal bo spodbujal sodelovanje javnega in zasebnega sektorja, ki si bosta izmenjavala informacije o možnostih, izboljšal pa bo tudi upoštevanje rokov razpisov dodeljevanja, izpolnjevanja in plačevanja naročil. Nazadnje pa bo izboljšal dostop do informacij o vladnih postopkih javnega naročanja in njihovo preglednost (Breytenbach, 2011).

Čeprav je vlada glavni zagovornik strategije B-BBEE in razvoja MSMP ter največji naročnik blaga in storitev v državi, lahko pri pregledu njenih postopkov in stroškov naročanja ugotovimo, da s svojimi dejanji ne podpira svojih politik (Herrington in Overmeyer, 2006: 25). Izkazalo se je, da premalo sredstev namenja preferencialnemu naročanju, zlasti razvoju malih podjetij v lasti temnopoltih. Poleg tega je vlada vzbudila pričakovanja, da se bo na podlagi vladnih pobud dostop MSMP do trga izboljšal, vendar sama ni sposobna izvesti obljubljenih strategij in postopkov. Novejše podrobno poročilo o javnem naročanju v Južnoafriški republiki vsebuje več negativnih ugotovitev, povezanih z MSMP (Kaiser Associates, 2010). Zaradi težav z opredelitvijo MSMP in neustreznih postopkov zbiranja podatkov $\gg$ ni mogoče ustvariti jasne slike o javnih naročilih, oddanih MSMP v Južnoafrǐ̌ki republiki « (Kaiser Associates, 2010: i). Le nekaj vladnih organov dejansko naroča storitve od MSMP, in še to samo določene storitve. Čeprav preferencialno naročanje ministrstev podpira MSMP, vključno z zagotavljanjem informacij in s kratkimi plačilnimi roki, določeni centralizirani sistemi naročanja preprečujejo dodeljevanje velikih naročil MSMP. Nazadnje pa niti ni mehanizma, ki bi povezal različne vrste vladne pomoči, namenjene MSMP, s tržnim dostopom do javnih naročil. Čeprav je očitno, da MSMP pripisujejo velik pomen vladnim podpornim programom, namenjenim njihovemu razvoju, so v podpornih strukturah velike vrzeli ter neskladje med programi in dejanskimi potrebami MSMP (Kaiser Associates, 2010: v). Zaradi nepovezanosti in neurejenosti vladnih informacijskih sistemov ni na voljo natančnih podatkov o vrednosti in številu naročil, dodeljenih MSMP (Kaiser Associates, 2010). Na primer, »ni skupnega sistema zbiranja in upravljanja podatkov, prav tako ni funkcionalnih sistemov zbiranja podatkov zaradi različnih stopenj tehničnih zmogljivosti « (Kaiser Associates, 2010: 85). Več javnih naročil bi lahko bilo dodeljeno MSMP pri tistih izdelkih in storitvah, ki se lahko dobavijo v majhnih količinah (hrana in pijača), izdelkih, ki ne zahtevajo visoke usposobljenosti, tehnologije ali kapitala (vrtnarstvo, vzdrževanje in popravila), 
izdelkih, ki za kupce niso tvegani (pisarniške potrebščine), in podeželskih storitvah, pri katerih se izdelki trenutno lokalno ne dobavljajo, ker se to preprosto ne izplača (Kaiser Associates, 2010). Skrb vzbujajoče je, da se »trenutna zakonodaja s področja preferencialnega naročanja usmerja $\mathrm{k}$ podjetjem B-BBEE in ne k MSMP« (Kaiser Associates, 2010: 9).

V splošnem se ta premik kaže v poudarjanju vidikov B-BBEE $\mathrm{v}$ novih predpisih o javnem naročanju, ki so bili sprejeti junija 2011 in poskušajo politiko B-BBEE uskladiti z okvirnim zakonom o javnem naročanju (Mesatywa, 2011). Z vidika finančnega ministrstva naj bi se $s$ temi predpisi javna naročila oddajala MSMP » prednostno « in ne prek mehanizma javnih naročil za posebne namene. Kljub temu obstaja nevarnost, da bodo koristi od te prednostne oddaje naročil imela predvsem večja podjetja v lasti temnopoltih in ne dejanska cilja skupina MSMP.

\section{Sklep}

Oblikovanje dinamičnega urbanega gospodarskega sistema je izziv, $s$ katerim se spopadajo vlade in načrtovalci na afriški celini (Turok, 2010, 2012). Izbolǰ̌anje položaja in povečanje potenciala rasti manjših podjetij sta le en vidik ustvarjanja produktivnejšega urbanega gospodarstva. Izboljšanje položaja MSMP v lasti temnopoltih in njihova vključitev $\mathrm{v}$ formalno gospodarstvo sta bila v Južnoafriški republiki največja strateška izziva po padcu apartheida. Sta pomembno vprašanje gospodarskega razvoja mest in oblikovanja vključujočih mest (glej Grant, 2010; Rogerson, 2010, in Turok, 2012). Prvo desetletje izvajanja vladnih pobud za izboljšanje položaja MSMP v lasti temnopoltih je bilo polno razočaranj in večina teh podjetij ostaja na obrobju formalnega gospodarstva. V novih smernicah po letu 2006 se poudarja ustvarjanje priložnosti za MSMP pri dodeljevanju naročil zasebnega sektorja in krepitev njihovega položaja pri javnem naročanju. Trenutne vladne usmeritve pri zagotavljanju boljšega dostopa do teh tržnih priložnosti dajejo prednost mestnim MSMP, zaradi česar so podjetja zunaj mest v neugodnem položaju. Problem sektorske prikrajšanosti se rešuje s posredovanjem ustreznih informacij in pomočjo pri programih, povezanih s prednostnimi sektorji, ki kažejo možnost rasti; poleg tega bi se ta problem lahko reševal tudi z boljšim dostopom do tržnih priložnostih, ki jih ponujajo naročila javnega in zasebnega sektorja. Najbolj skrb vzbujajoča je nezadostna konkurenčnost, ki se rešuje samo $s$ pobudami, usmerjenimi v zagotavljanje raznolikosti dobaviteljev.

Južnoafriška vlada vedno znova priznava nujnost izboljšanja sposobnosti MSMP v lasti temnopoltih, da poslujejo $\mathrm{v}$ formalnem gospodarstvu. To zahteva niz povezanih posegov na področju financ in predpisov ter zajema novejše pobude za izboljšanje tržnega dostopa (Osiba Research, 2011). Analiza kaže, da vlada priznava svoje omejitve pri izvajanju ukrepov za izboljšanje položaja MSMP in oblikovanja konkurenčnih MSMP v lasti temnopoltih. Sprejela je odločitev o vzpostavitvi obetavnega partnerstva z zasebnim sektorjem, da bi povečala raznolikost dobaviteljev, kar temelji na poslovnih razlogih širjenja povezav in ne na sistemu uravnoteženih kazalnikov B-BBEE. Poleg tega poskuša vlada izvajati tisto, kar zagovarja, ter uporabiti svoje možnosti izvajanja javnih naročil in tako pomagati MSMP v lasti temnopoltih.

Christian M. Rogerson

University of Johannesburg, School of Tourism and Hospitality,

Južnoafriška republika

E-pošta: crogerson@uj.ac.za

\section{Zahvala}

Avtor se zahvaljuje urednikom revije in recenzentom za pomoč pri poudarjanju urbanističnega vidika članka. Članek je bil napisan $s$ finančno pomočjo nacionalnega raziskovalnega sklada $v$ Pretorii. Krajša različica članka je bila predstavljena na konferenci z naslovom Association of American Geographers Annual Meeting, ki je potekala aprila 2013 v Los Angelesu.

\section{Viri in literatura}

Adobor, H., in McMullen, R. (2007): Supplier diversity and supply chain management: A strategic approach. Business Horizons, 50(3), str. 219229. DOI: 10.1016/j.bushor.2006.10.003

Altman, M. (2010): Procurement will boost the small business sector. Municipal Focus, 2(3), str. 40-43.

Bates, T. (2001): Minority business access to mainstream markets. Journal of Urban Affairs, 23(1), str. 41-56. DOI: 10.1111/0735-2166.00074

Bolton, P. (2006): Government procurement as a policy tool in South Africa. Journal of Public Procurement, 6(3), str. 193-217.

Bolton, P. (2008): Protecting the environment through public procurement: The case of South Africa. Natural Resources Forum, 32(1), str. 1-8. DOI: 10.1111/j.1477-8947.2008.00171.x

Boraine, A., Crankshaw, O., Engelbrecht, C., Gotz, G., Mbanga, S., Narsoo, M., in Parnell, S. (2006): The state of South African cities a decade after democracy. Urban Studies, 43(2), str. 259-284. DOI: 10.1080/00420980500416990

Botha, M., in Van Vuuren, J. (2006): Identifying the criteria that large corporations (JSE-listed) make use of when dealing with Broad Based Black Economic Empowered (BBBEE) small and medium-sized enterprises. Neobjavljeno posvetovalno poročilo. Johannesburg.

Breytenbach, T. (2011): Integrated Small Enterprises Supplier Development Programme. Pretoria, Small Enterprise Development Agency.

Bryceson, D., in Potts, D. (ur.) (2006): African urban economies: Viability, vitality or vitiation? Basingstoke, Palgrave.

Freund, B. (2010): Is there such a thing as a post-apartheid city? Urban Forum, 21(3), str. 283-298. DOI: 10.1007/s12132-010-9087-4

Grant, R. (2010): Working it out: Labour geographies of the poor in Soweto, South Africa. Development Southern Africa, 27(4), str. 595-612. DOI: 10.1080/0376835X.2010.508595 
Herrington, M. D., in Overmeyer, T. (2006): Study on the procurement relationship between large corporations and mainly black owned or empowered SMEs. Raziskovalno poročilo. Johannesburg, University of Cape Town, Graduate School of Business.

House-Soremekun, B. (2007): The impact of minority set-aside programs on black business success in Cleveland, Ohio: Implications for public policy. Western New England Law Review 30(19), str. 19-37.

Ismael, A., in Haselau, K. (2010): SASDC operations. Prispevek je bil predstavljen na delavnici z naslovom SASDC Steering Committee Workshop, ki je potekala 26. novembra v Sandtonu v Južnoafriški republiki. Tipkopis.

Jenkins, B. (2007): Expanding economic opportunity: The role of large firms. Washington DC, International Finance Corporation, International Business Leaders Forum and the CSR Initiative of the Harvard Kennedy School.

Jenkins, B., in Ishikawa, E. (2009): Business linkages: Enabling access to markets at the base of the pyramid. Washington DC, International Finance Corporation, International Business Leaders Forum and the CSR Initiative of the Harvard Kennedy School.

Joseph, G. (2010): SASDC strategy: Intent and leadership. Prispevek je bil predstavljen na delavnici z naslovom SASDC Steering Committee Workshop, ki je potekala 26. novembra v Sandtonu v Južnoafriški republiki. Tipkopis.

Juggernauth, S., Rampersad, R., in Reddy, K. (2011): Corporate responsibility for socio-economic transformation: A focus on broad-based black economic empowerment and its implementation in South Africa. African Journal of Business Management, 5(20), str. 8224-8234.

Južnoafriški svet za raznolikost dobaviteljev (2011): Strategic Plan 2011-2016. Johannesburg.

Kaiser Associates (2010): Public sector procurement from small, medium and micro enterprises (SMMEs). Cape Town.

Kessides, C. (2007): The urban transition in sub-Saharan Africa: Challenges and opportunities. Environment and Planning C, 25(4) str. 466-485. DOI: $10.1068 / c 3 p$

Konferenca Združenih narodov o trgovini in razvoju (2006): Business Linkages Programme Guidelines. New York in Ženeva.

Ligthelm, A. (2012): The viability of informal micro businesses in South Africa: A longitudinal analysis (2007 to 2011). African Journal of Business Management, 6(46), str. 11416-11425.

Mahmood, S. A. I. (2010): Public procurement and corruption in Bangladesh: Confronting the challenges and opportunities. Journal of Public Administration and Policy Research, 2(6), str. 103-111.

Meagher, K. (2010): The tangled web of associational life: Urban governance and the politics of popular livelihoods in Nigeria. Urban Forum, 21(3), str. 299-313.

Mesatywa, N. (2011): Levering public procurement. Prispevek je bil predstavljen na konferenci z naslovom Annual Small Business Summit, ki je potekala 12. oktobra v Bloemfonteinu v Južnoafriški republiki. Tipkopis.

Ministrstvo za gospodarski razvoj (2010): The New Growth Path framework. Pretoria.

Ministrstvo za trgovino in industrijo (2006): Integrated Small-Enterprise Development Strategy: Unlocking the potential of South African entrepreneurs. Pretoria.

Ministrstvo za trgovino in industrijo (2011): Medium-Term Strategic Plan. Pretoria.

Nacionalna poslovna pobuda (2006a): Report on commercial linkages between large enterprises and small enterprises in South Africa. Unpublished research report. Johannesburg.

Nacionalna poslovna pobuda (2006b): Support by large enterprises of small enterprise suppliers in the value chain: $A$ summary of findings and key proposals. Neobjavljeno raziskovalno poročilo. Johannesburg.

Nel, E., in Rogerson, C. M. (ur.) (2005): Local economic development in the developing world. New Brunswick, NJ, Transaction Publishers.

Orser, B. (2009): Procurement strategies to support women-owned enterprises. Ottawa, Canada Works Limited.

Osiba Research (2011): Rethinking small business support in South Africa. Neobjavljeno raziskovalno poročilo. Pretoria.

Ram, M., in Smallbone, D. (2003a): Supplier diversity initiatives and diversification of ethnic minority businesses in the UK. Policy Studies, 24(4), str. 187-204. DOI: 10.1080/0144287042000216117

Ram, M., in Smallbone, D. (2003b): Policies to support ethnic minority enterprise: The English experience. Entrepreneurship and Regional Development, 15(2), str. 151-166. DOI: 10.1080/0898562032000075177

Rogerson, C. M. (1997): Globalization or informalization? African urban economies in the 1990s. V: Rakodi, C. (ur.): Managing urban growth in Africa, str. 337-370. Tokio, United Nations University Press.

Rogerson, C. M. (2004a): Ten years of changing development planning in a democratic South Africa. International Development Planning Review, 26(4), str. 355-358. DOI: 10.3828/idpr.26.4.1

Rogerson, C. M. (2004b): The impact of the South African government's SMME programmes: a ten year review, Development Southern Africa, 21(5), str. 765-784. DOI: 10.1080/0376835042000325697

Rogerson, C. M. (2004c): Urban tourism and small tourism enterprise development in Johannesburg: The case of township tourism. GeoJournal, 60(3), str. 249-257. DOI: 10.1023/B:GEJO.0000034732.58327.b6

Rogerson, C. M. (2006): The market development approach to SMME development: Implications for local government in South Africa, Urban Forum, 17(1), str. 54-78.

Rogerson, C. M. (2008): Tracking SMME development in South Africa: Issues of finance, training and the regulatory environment. Urban Forum, 19(1), str. 61-81.

Rogerson, C. M. (2010): Local economic development in South Africa: Key strategic challenges. Development Southern Africa, 27(4), str. 481-495. DOI: $10.1080 / 0376835 X .2010 .508580$

Rogerson, C. M. (2011): Tracking local economic development policy and practice in South Africa, 1994-2009. Urban Forum, 22(2), str. 149-168.

Rogerson, C. M. (2012): Supplier diversity: A new phenomenon in private sector procurement in South Africa. Urban Forum, 23(3), str. 279-297.

Rogerson, C. M., in Rogerson, J. M. (2010): Local economic development in Africa: Global context and research directions, Development Southern Africa, 27(4), str. 465-480. DOI: 10.1080/0376835X.2010.508577

Rogerson, C. M., in Rogerson, J. M. (2012): Business development and local economic development in South Africa: Addressing the disconnect. Acta Academica, 44(2), str. 41-69.

Schenck, R., in Blaauw, P. F. (2011): The work and lives of street waste pickers in Pretoria - A case study of recycling in South Africa's urban informal economy. Urban Forum, 22(4), str. 411-430.

Skae, O. (2006): Preferential procurement - A needs assessment of large scale enterprises and what constitutes best practice: A South African perspective. Neobjavljeno raziskovalno poročilo. Johannesburg.

Sonfield, M. (2010): Ethnic minority businesses and targeted assistance programs in the U.S. and the UK: A comparison and implications. Small Business Institute National Proceedings, 34(Winter), str. 11-17.

Thai, K. V. (2001): Public procurement re-examined. Journal of Public Procurement, 1(1), str. 9-50.

Thornton, A, in Rogerson, C. M. (2013): African cities and the millennium development goals: A case for applied geography. Applied Geography, 36(1), str. 1-2. DOI: 10.1016/j.apgeog.2012.09.004 
Timm, S. (2011): How South Africa can boost support to small businesses: Lessons from Brazil and India. Pretoria, Trade and Industrial Policy Secretariat.

Toomey, D. C. (1998): South African small business growth through interfirm linkages. Unpublished doctoral thesis. Grahamstown, Rhodes University, Faculty of Humanities.

Turok. I. (2010): The prospects for urban African economies. Urban Research and Practice, 3(1), str. 12-24.

Turok, I. (2012): Unleashing the economic potential of African cities. Prispevek je bil predstavljen na delavnici z naslovom UN Habitat Workshop, ki je potekala od 23. do 24. februarja v Cape Townu v Južnoafriški republiki. Tipkopis.

Turok, I., in Parnell, S. (2009): Reshaping cities, rebuilding nations: The role of national urban policies. Urban Forum, 20(2), str. 157-174.

Urad predsednika Južnoafriške republike (2011): National development plan: Vision for 2030. Pretoria, National Planning Commission.

Urban, B. (2006): Entrepreneurship in the rainbow nation. Journal of Developmental Entrepreneurship, 11(3), str. 171-186.

DOI: 10.1142/S1084946706000386 